\title{
Hubungan Pengetahuan Dengan Kunjungan Kelas Ibu Hamil Di Desa Jogomulyan Kecamatan Tirtoyudo Kabupaten Malang
}

\author{
Atik Muji Rahayu, Rahmania Ambarika*, Arina Chusnatayaini \\ Institut Ilmu Kesehatan STRADA Indonesia \\ Corresponding author: Rahmania Ambarika (rahmaniaambarika@gmail.com) \\ Received: December, 16 2019; Accepted: January, 19 2020; Published: March, 152020
}

\begin{abstract}
ABSTRAK
Kelas Ibu Hamil ini merupakan sarana untuk belajar bersama tentang kesehatan bagi ibu hamil, dalam bentuk tatap muka dalam kelompok untuk meningkatkan pengetahuan dan keterampilan mengenai kehamilan, perawatan kehamilan, persalinan, perawatan nifas, perawatan bayi baru lahir, mitos, penyakit menular dan akte kelahiran. Faktor kurangnya pengetahuan ibu hamil menyebabkan kunjungan ibu hamil di kelas ibu hamil mejadi sangat rendah. Hal ini mengakibatkan ibu hamil tidak mendapatkan manfaat dari kegiatan tersebut. Penelitian bertujuan mengetahui hubungan tingkat hubungan pengetahuan dengan kunjungan kelas ibu hamil. Penelitian deskriptif korelasional dengan pendekatan cross sectional. Populasi seluruh Ibu Hamil trimester 3 di Desa Jogomulyan Kecamatan Tirtoyudo Kabupaten Malang, pada bulan Februari 2019. Menggunakan teknik Purposive sampling, besar sampel 25 responden. Pengumpulan data dengan instrumen kuesioner. Hasil penelitian menunjukkan 64\% tingkat pengetahuan cukup dan $72 \%$ mengikuti kelas ibu hamil. Hasil uji Chi square didapatkan $\mathrm{p}=0,000$, ada hubungan antara tingkat pengetahuan dengan kunjungan kelas ibu hamil. Kunjungan kelas ibu hamil merupakan wujud perilaku ibu hamil yang dalam pelaksanaannya berkaitan erat dengan pengetahuan yang dimiliki. Hal ini berarti bahwa semakin tinggi tingkat pengetahuan yang dimiliki semakin tinggi pula kunjungan kelas ibu hamil. Upaya meningkatkan kunjungan kelas ibu hamil dapat dilakukan dengan meningkatkan pengetahuan ibu hamil melalui pendidikan kesehatan.
\end{abstract}

Kata Kunci: Pengetahuan, Kunjungan Kelas Ibu Hamil, Purposive Sampling

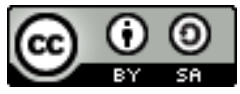

This is an open-acces article distributed under the terms of the Creative Commons Attribution-ShareAlike 4.0 International License.

\section{PENDAHULUAN}

Program pembangunan kesehatan di Indonesia dewasa ini masih diprioritaskan pada upaya peningkatan derajat kesehatan Ibu dan anak, terutama pada kelompok yang paling rentan kesehatan yaitu ibu hamil, bersalin dan bayi pada masa perinatal. Kelas Ibu Hamil ini merupakan sarana untuk belajar bersama tentang kesehatan bagi ibu hamil, dalam bentuk tatap muka dalam kelompok yang bertujuan untuk meningkatkan pengetahuan dan keterampilan ibu-ibu mengenai kehamilan, perawatan kehamilan, persalinan, perawatan nifas, perawatan bayi baru lahir, mitos, penyakit menular dan akte kelahiran. Fenomena yang ada di masyarakat, kunjungan ibu hamil di kelas ibu hamil saat ini masih sangat rendah, padahal 
banyak sekali manfaat yang akan diperoleh ibu hamil jika mengikuti kelas ibu hamil, salah satu diantaranya adalah mengurangi resiko kematian ibu dan janin (Kemenkes RI, 2017).

Dalam 3 tahun terakhir, AKI dan AKB di Indonesia hingga tahun 2017 masih cukup mengkhawatirkan. Jumlah kasus kematian Bayi turun dari 33.278 di tahun 2015 menjadi 32.007 pada tahun 2016, dan di tahun 2017 di semester I sebanyak 10.294 kasus. Demikian pula dengan angka kematian Ibu turun dari 4.999 tahun 2015 menjadi 4912 di tahun 2016 dan di tahun 2017 (semester I) sebanyak 1712 kasus (Kemenkes RI, 2017).

Berdasarkan data Dinas Kesehatan Provinsi Jawa Timur tahun 2014, Angka Kematian Ibu (AKI) di Provinsi Jawa Timur mencapai 93,52 per 100.000 kelahiran hidup. Angka ini mengalami penurunan dibandingkan tahun 2013 yang mencapai 97,39 per 100.000 kelahiran hidup (Yohanes, 2017).

Hingga tahun 2016, angka AKI dan AKB di Kabupaten Malang masih cukup tinggi. Pada akhir 2016 tercatat 15 kasus kematian ibu melahirkan. dalam 3 tahun terakhir, angka kematian ibu di Kabupaten Malang rata-rata 21 orang per tahun. Kondisi ini disebabkan banyak ibu hamil berisiko yang tidak terpantau dan tidak ditangani dengan baik dan benar (Yohanes, 2017).

Berdasarkan hasil studi pendahuluan di Desa Jogomulyan Kecamatan Tirtoyudo, pada bulan Desember 2019, dari hasil pengamatan diketahui kondisi geografis Desa Jogomulyan yang bergunung-gunung, dengan akses transportasi yang masih kurang mamadai. Dari hasil wawancara dengan bidan desa setempat, diketahui jumlah ibu hamil pada tahun 2018 di Desa Jogomulyan sebanyak 75 orang, di desa ini terdapat kelas ibu hamil yang dikelola oleh Bidan Desa dengan dibantu seorang kader kesehatan. Berdasarkan hasil wawancara dengan 12 orang tersebut, 6 orang (50\%) mengatakan selelu mengikuti kegiatan kelas ibu hamil, 4 orang (25\%) mengatakan jarang mengikuti, dan 4 orang $(25 \%)$ mengatakan belum pernah mengikuti kelas ibu hamil, dengan alasan jarak rumah mereka yang cukup jauh dari lokasi pelaksanaan kelas ibu hamil. Hal tersebut mengindikasikan bahwa kunjungan di kelas ibu hamil di desa Jogomulyan masih sangat rendah.

Rendahnya pengetahuan ibu hamil mengenai manfaat kelas ibu hamil, jarak tempat tinggal yang jauh dari lokasi pelaksanaan kelas ibu hamil, kurangnya dukungan suami dan keluarga, rendahnya penghasilan keluarga, serta kurang disediakannya media informasi mengenai kelas ibu hamil di tempat pelayanan kesehatan, menyebabkan rendahnya kunjungan di kelas ibu hamil. Menurut Notoatmodjo (2013), perilaku seseorang ditentukan oleh pengetahuan yang dimilikinya. Perubahan perilaku ditentukan oleh konsep manfaat, artinya bila seseorang mengetahui ada manfaat terhadap kesehatan maka secara sadar orang tersebut akan mempraktikkan perilaku tersebut. Kunjungan ibu hamil di kelas senam hamil merupakan bentuk perilaku, sebagai upaya mengurangi resiko persalinan

Dampak apabila ibu hamil yang tidak turut serta dalam kegiatan kelas ibu hamil akan mengalami kerugian, yaitu tidak memperoleh hasil yang diharapkan dari kelas ibu hamil, berinteraksi dan berbagi pengalaman antar peserta (ibu hamil dengan ibu hamil) dan ibu hamil dengan bidan/tenaga kesehatan tentang kehamilan, perawatan kehamilan, persalinan, perawatan nifas, perawatan bayi, mitos/kepercayaan/adat istiadat setempat, penyakit menular dan akte kelahiran. Melalui perawatan kehamilan yang dilakukan di kelas ibu hamil diharapkan dapat menurunkan resiko komplikasi persalinan, dengan kata lain ibu hamil yang tidak mengikuti kelas ibu hamil berpeluang lebih besar mengalami komplikasi persalinan daripada yang mengikuti kegiatan tersebut (Kemenkes RI, 2017).

Upaya meningkatkan kunjungan di kelas ibu hamil dapat dilakukan melalui seminar kesehatan mengenai pentingnya mengikuti kelas ibu hamil, serta mendatangkan ahli kandungan (dokter spesialis kandungan). Puskesmas melakukan sosialisasi kepada masyarakat tentang manfaat kelas ibu hamil melalui upaya promosi kesehatan, serta lebih 
melibatkan kader untuk memberikan informasi mengenai kelas ibu hamil kepada warganya dengan memanfaatkan sosial media (Damayanti, 2018).

Berdasarkan permasalahan peneliti ingin meneliti hubungan tingkat pengetahuan dengan kunjungan kelas ibu hamil di Desa Jogomulyan Kecamatan Tirtoyudo Kabupaten Malang.

\section{Tujuan Penelitian}

Untuk mengetahui hubungan tingkat hubungan pengetahuan dengan kunjungan kelas ibu hamil.

\section{METODE PENELITIAN}

Metode penelitian ini menggunakan metode studi analitik observasiobal dengan pendekatan cross sectional dengan 25 responden. Teknik sampling pada penelitian ini adalah purposive sampling. Teknik pengolahan data statistik dilakukan dengan SPSS 20.0 mengggunakan Chi square.

\section{HASIL PENELITIAN}

Tabel 1. Karakteristik Responden

\begin{tabular}{|c|c|c|c|}
\hline No & Kategori & $\Sigma \mathbf{N}$ & $\%$ \\
\hline \multirow[t]{6}{*}{1} & Pendidikan: & & \\
\hline & Tidak sekolah & 2 & 8 \\
\hline & $\mathrm{SD}$ & 3 & 12 \\
\hline & SMP & 4 & 16 \\
\hline & SMA/SMK & 11 & 44 \\
\hline & Perguruan tinggi & 5 & 20 \\
\hline \multirow[t]{5}{*}{2} & Pekerjaan: & & \\
\hline & Petani & 6 & 24 \\
\hline & ASN & 4 & 16 \\
\hline & ibu rumah tangga & 8 & 32 \\
\hline & Wiraswasta & 5 & 20 \\
\hline \multirow[t]{4}{*}{3} & Usia: & & \\
\hline & $<20$ tahun & 3 & 12 \\
\hline & 20-35 tahun & 18 & 72 \\
\hline & $>35$ tahun & 4 & 16 \\
\hline \multirow[t]{5}{*}{4} & Paritas: & & \\
\hline & Kehamilan ke-1 & 10 & 40 \\
\hline & Kehamilan ke -2 & 8 & 32 \\
\hline & Kehamilan ke-3 & 5 & 20 \\
\hline & Kehamilan ke- 4 dst & 2 & 8 \\
\hline
\end{tabular}

Tabel 1 menjelaskan hampir setengah dari responden (44\%) berpendidikan SMA/SMK, hampir setengah dari responden (32\%) bekerja sebagai ibu rumah tangga, sebagian besar responden (72\%) berusia 20-35 tahun dan hampir setengah dari responden (40\%) merupakan kehamilan pertama. 


\section{Hasil Uji Statistik}

Tabel 2. Uji Chi Square

\begin{tabular}{lc}
\hline \multicolumn{2}{c}{ Skor kunjungan } \\
\hline Skor & Pearson Chi Square $=20,394$ \\
\cline { 2 - 2 } Pengetahuan & p value $=0,000$ \\
\cline { 2 - 2 } & $\mathrm{N}=25$
\end{tabular}

Tabel 2 menjelaskan jumlah responden $(\mathrm{N})=25$, Pearson Chi Square $=20,394$ dan $p$ value $=0,000$, ada hubungan yang bermakna antara tingkat pengetahuan dengan kunjungan kelas ibu hamil di Desa Jogomulyan Kecamatan Tirtoyudo Kabupaten Malang.

\section{PEMBAHASAN}

\section{Tingkat Pengetahuan Ibu Hamil tentang Kelas Ibu Hamil}

Berdasarkan hasil penelitian terhadap 25 ibu hamil di Desa Jogomulyan Kecamatan Tirtoyudo Kabupaten Malang, diketahui sebagian besar (64\%) tingkat pengetahuan cukup, data karakteristik pendidikan menunjukkan hampir setengah (44\%) berpendidikan SMA/SMK, dengan karakteristik pekerjaan menunjukkan hampir setengah (32\%) ibu rumah tangga. Hasil ini selaras dengan penelitian Ristyanto (2015), yang menyimpulkan ada hubungan antara tingkat pendidikan formal dan pengetahuan orang tua balita di Puskesmas Gatak, dengan $p$ value $=0,000$.

Pengetahuan sangat erat kaitannya dengan pendidikan. Seseorang dengan pendidikan tinggi akan semakin luas pengetahuannya. Peningkatan pengetahuan tidak mutlak diperoleh dari pendidikan formal,akan tetapi juga dapat diperoleh dari pendidikan non formal (Maramis et al,2012).

Rendahnya pengetahuan ibu hamil mengenai kelas hamil disebabkan tingkat pendidikan mereka yang hanya lulusan SMA, serta pekerjaan sebagian besar dari mereka yang sebagian besar merupakan ibu rumah tangga. Tingkat pendidikan dan pekerjaan merupakan faktor yang berpengaruh terhadap pengetahuan.

\section{Kunjungan Kelas Ibu Hamil}

Berdasarkan hasil penelitian terhadap 25 ibu hamil di Desa Jogomulyan Kecamatan Tirtoyudo Kabupaten Malang, diketahui sebagian besar (72\%) mengikuti kelas ibu hamil. Berdasarkan tingkat pendidikan diketahui hampir setengah (44\%) berpendidikan SMA/SMK, sedangkan karakteristik pekerjaan menunjukkan hampir setengah $(32 \%)$ bekerja sebagai petani. Hasil ini selaras dengan penelitian Febyanti (2012), yang menyimpulkan bahwa pekerjaan merupakan salah satu faktor yang mempengaruhi kepatuhan ibu hamil dalam mengikuti kegiatan kelas ibu hamil. Menurut Febyanti tingginya angka kunjungan kelas ibu hamil disebabkan sebagian besar dari mereka bekerja sebagai ibu rumah tangga, sehingga cenderung lebih banyak memiliki waktu luang untuk mengikuti kegiatan senam hamil.

Faktor-faktor yang mempengaruhi perilaku hidup sehat dibagi menjadi 3 bagian yaitu faktor predisposisi (umur, pekerjaan, tingkat pengetahuan dan tingkat pendidikan), faktor pemungkin (fasilitas dan sarana) dan faktor penguat (dukungan tokoh masyarakat, perilaku petugas kesehatan, dan tersampaikan atau tidaknya promosi kesehatan). Kunjungan ibu hamil di kelas hamil merupakan salah satu wujud dari perilaku kesehatan, merupakan sarana melakukan kegiatan bagi ibu hamil, berdiskusi dan tukar pengalaman untuk meningkatkan pengetahuan dan keterampilan tentang kehamilan, persalinan, perawatan nifas dan perawatan bayi baru lahir melalui praktek yang difasilitasi petugas kesehatan (Notoatmodjo, 2013).

Sebagian besar ibu hamil hadir dikelas ibu hamil disebabkan sebagian besar dari mereka merupakan ibu rumah tangga sehinga memiliki lebih banyak waktu untuk mengikuti kegiatan kelas ibu hamil. 


\section{Hubungan Tingkat Pengetahuan dengan Kunjungan Kelas Ibu Hamil}

Hasil uji statistik Chi Square menunjukkan $p$ value $=0,000$, ada hubungan yang bermakna antara tingkat pengetahuan dengan kunjungan kelas ibu hamil di Desa Jogomulyan Kecamatan Tirtoyudo Kabupaten Malang. Hasil ini berbeda dengan hasil penelitian Damayanti (2018), yang menyimpulkan bahwa tidak terdapat hubungan antara tingkat pengetahuan dengan kunjungan kelas ibu hamil ( $\mathrm{p}=0,268)$.

Menurut Notoatmodjo (2013), perilaku adalah respon individu terhadap suatu stimulus atau suatu tindakan yang dapat diamati dan mempunyai frekuensi spesifik, durasi dan tujuan baik disadari maupun tidak. Perilaku merupakan kumpulan berbagai faktor yang saling berinteraksi.Sering tidak disadari bahwa interaksi tersebut amat kompleks sehingga kadangkadang kita tidak sempat memikirkan penyebab seseorang menerapkan perilaku tertentu. Perilaku dari pandangan biologis adalah merupakan suatu kegiatan atau aktivitas organisme yang bersangkutan. Secara umum, perilaku seseorang atau masyarakat ditentukan oleh pengetahuan, sikap, kepercayaan, tradisi, dan sebagainya dari orang atau masyarakat yang bersangkutan. Selain itu, ketersediaan fasilitas, sikap dan perilaku petugas kesehatan terhadap kesehatan akan mendukung dan memperkuat terbentuknya perilaku.

Ada hubungan yang bermakna antara tingkat pengetahuan dengan kunjungan kelas ibu hamil disebabkan karena kunjungan kelas ibu hamil merupakan wujud perilaku ibu hamil. Perilaku tersebut terjadi karena adanya keinginan ibu hamil untuk menghindari resiko persalinan.

\section{KESIMPULAN}

Berdasarkan hasil penelitian terhadap 25 Ibu hamil di Desa Jogomulyan Kecamatan Tirtoyudo Kabupaten Malang, disimpulkan bahwa

1. Tingkat pengetahuan mengenai kelas ibu hamil sebagian besar (64\%) cukup.

2. Kunjungan kelas ibu hamil sebagian besar (72\%) mengikuti kelas ibu hamil

3. Ada hubungan antara tingkat pengetahuan dengan kunjungan kelas ibu hamil dengan $p$ value $=0,000$.

\section{SARAN}

\section{Bagi Puskesmas}

Agar semakin meningkatkan promosi kesehatan untuk meningkatkan kesediaan ibu hamil mengikuti kelas hamil dalam rangka menurunkan resiko persalinan. Upaya tersebut dapat dilakukan dengan melakukan sosialisasi manfaat dan kegiatan apa saja di kelas ibu hamil di organisasi-organisasi sosial kemasyarakatan seperti Jamaah tahlil, Dasa wisma, sehingga diharapkan semakin banyak ibu hamil yang bersedia mengikuti kegiatan kelas hamil.

\section{Bagi Institusi Pendidikan Ilmu Kebidanan}

Agar lebih meningkatkan kualitas dan kuantitas diskusi dan kajian ilmiah berkaitan dengan fenomena kelas ibu hamil dan manfaatnya dalam mengurangi resiko persalinan, sebagai bagian dari pelaksanaan Tridharma perguruan tinggi.

\section{Bagi Peneliti}

Agar memanfaatkan hasil penelitian ini sebagai data dasar penelitian selanjutnya, terutama yang berkaitan dengan kelas ibu hamil dan kaitannya dangan manfaat yang diperoleh ibu hamil jika mengikuti kegiatan ini.

\section{Bagi responden ibu hamil}

Agar semakin rajin mengikuti kegiatan kelas ibu hamil mengingat demikian besar manfaatnya bagi persiapan ibu menghadapi proses persalinan. 


\section{DAFTAR PUSTAKA}

Damayanti. (2018). Faktor-Faktor Yang Berhubungan Dengan Motivasi Ibu Hamil Mengikuti Kelas Ibu Hamil Di Wilayah Kerja Puskesmas Sukoharjo Kabupaten Sukoharjo. Skripsi. Surakarta : Program Studi Kesehatan Masyarakat Fakultas Ilmu Kesehatan Universitas Muhammadiyah.

Febyanti N K, 2012, Hubungan Pengetahuan Ibu Hamil tentang Antenatal Care terhadap Perilaku Kunjungan Kehamilan. Jurnal Keperawatan Soedirman (The Soedirman Journal of Nursing), Volume 7, No.3, November 2012.

Kemenkes RI. (2017). Inilah Capaian Kinerja Kemenkes RI Tahun 2015- 2017 (http://www.depkes.go.id/article/view/17081700004/-inilah-capaian-kinerja-kemenkesri-tahun-2015--2017.html/ (diakses tanggal 17 januari 2018).

Maramis P.A., Ismanto A.Y., Babakal A., 2013. Hubungan Tingkat Pendidikan dan Pengetahuan Ibu Tentang ISPA dengan KemampuanIbuMerawat Balita ISPA pada Balita di Puskesmas Bahu Kota Manado. Ejournal Keperawatan (e-Kp) Volume 1. Nomor 1. Agustus 2013. Email : Mitha_lv6017@ymail.com.

Notoatmodjo S., (2013), Kesehatan Masyarakat, Ilmu \& Seni - Ed Revisi, Rineka Cipta, Jakarta.

Ristiyanto R., (2015), Hubungan Antara Tingkat Pendidikan Formal Dan Pengetahuan Orang Tua Tentang Ispa Pada Balita Di Puskesmas Gatak. Skripsi. Fakultas Kedokteran Universitas Muhammadiyah Surakarta.

Yohanes. (2017). Per Tahunnya. 21 Ibu Meninggal Dunia di Kabupaten Malang. Ini Penyebabnya. (http://suryamalang.tribunnews.com/2017/05/10/per-tahunnya-21-ibumeninggal-dunia-di-kabupaten-malang-ini-penyebabnya/ (diaksestanggal17Januari2019). 